\title{
Maternal 3'UTRs: from egg to onset of zygotic transcription in Atlantic cod
}

\author{
Lene Kleppe ${ }^{1 *}$, Rolf B Edvardsen ${ }^{1}$, Heiner Kuhl ${ }^{2}$, Ketil Malde ${ }^{1}$, Tomasz Furmanek ${ }^{1}$, Øyvind Drivenes ${ }^{1}$, \\ Richard Reinhardt ${ }^{3}$, Geir L Taranger ${ }^{1}$ and Anna Wargelius ${ }^{1}$
}

\begin{abstract}
Background: Zygotic transcription in fish embryos initiates around the time of gastrulation, and all prior development is initiated and controlled by maternally derived messenger RNAs. Atlantic cod egg and embryo viability is variable, and it is hypothesized that the early development depends upon the feature of these maternal RNAs. Both the length and the presence of specific motifs in the $3^{\prime} U T R$ of maternal RNAs are believed to regulate expression and stability of the maternal transcripts. Therefore, the aim of this study was to characterize the overall composition and 3'UTR structure of the most common maternal RNAs found in cod eggs and pre-zygotic embryos.

Results: 22229 Sanger-sequences were obtained from 3'-end sequenced cDNA libraries prepared from oocyte, 1-2 cell, blastula and gastrula stages. Quantitative PCR revealed that EST copy number below 9 did not reflect the gene expression profile. Consequently genes represented by less than 9 ESTs were excluded from downstream analyses, in addition to sequences with low-quality gene hits. This provided 12764 EST sequences, encoding 257 unique genes, for further analysis. Mitochondrial transcripts accounted for $45.9-50.6 \%$ of the transcripts isolated from the maternal stages, but only $12.2 \%$ of those present at the onset of zygotic transcription. $3^{\prime} U T R$ length was predicted in nuclear sequences with poly-A tail, which identified 191 3'UTRs. Their characteristics indicated a more complex regulation of transcripts that are abundant prior to the onset of zygotic transcription. Maternal and stable transcripts had longer 3'UTR (mean 187.1 and 208.8 bp) and more 3'UTR isoforms (45.7 and 34.6\%) compared to zygotic transcripts, where $15.4 \%$ had $3^{\prime} U T R$ isoforms and the mean 3'UTR length was 76 bp. Also, diversity and the amount of putative polyadenylation motifs were higher in both maternal and stable transcripts.

Conclusions: We report on the most pronounced processes in the maternally transferred cod transcriptome. Maternal stages are characterized by a rich abundance of mitochondrial transcripts. Maternal and stable transcripts display longer 3'UTRs with more variation of both polyadenylation motifs and $3^{\prime} U T R$ isoforms. These data suggest that cod eggs possess a complex array of maternal RNAs which likely act to tightly regulate early developmental processes in the newly fertilized egg.
\end{abstract}

Keywords: 3'UTR, Sequence/EST filtering, External spiking, Transcriptome, Teleost, Embryonic development

\section{Background}

A series of complex biological processes take place over time in order to transform a newly fertilized egg into a fully grown organism. At the very beginning of embryonic development, these biological processes are completely controlled by maternally derived materials. Maternally deposited messenger RNAs (maternal RNAs) and proteins drive embryo development until the zygote

\footnotetext{
* Correspondence: lene.kleppe@imr.no

${ }^{1}$ Institute of Marine Research, P. O. Box 1870, Nordnesgaten 50, 5817 Bergen, Norway

Full list of author information is available at the end of the article
}

is able to transcribe its own RNA. The link between maternal mRNAs and the ability of the embryo to develop normally is of high relevance in many fields, including that of aquaculture. For aquaculture species including Atlantic cod (Gadus morhua L.), there is a necessity to produce viable eggs and embryos to ensure both economic- and welfare aspects. However, variable egg viability is common, especially in marine farmed fish species (Reviewed in $[1,2]$ ). Also, egg viability in cod varies between batches within one spawning season [3]. Although a number of studies have identified different factors that may affect egg viability, as well as indicators

\section{Biomed Central}


that could help in determining if an egg batch is of good or bad shape (reviewed in [4]), the complete picture is far from fully understood. During oogeneis transcribed maternal RNAs are stored in dormant complexes for translation just before or after fertilization [5]. The activation of translation is regulated and starts with polyadenlyation of the stored mRNA. A recent paper in zebrafish reports that $30 \%$ of maternal transcripts are polyadenylated prior to fertilization while $70 \%$ are progressively polyadenylated after fertilization [6]. In several vertebrates including Xenopus, zebrafish and mouse, elements (motifs) in the 3'UTR confer translation initiation and mRNA stability or degradation $[5,7,8]$. These 3'UTR elements bind specific proteins and/or proteincomplexes which mediate stability, translation and degradation of maternal RNAs [5].

As development progresses, maternal transcripts gradually mix with zygotic transcripts and many are degraded, in line with the first events of embryogenesis. This maternal to zygotic transition (MZT) is characterized by a gradual degradation of maternal mRNAs and proteins, followed by transcriptional activation of the zygotic genome (reviewed in [9]). MZT coincides with cell cycle lengthening and loss of cell synchrony at cell cycle 13 in Xenopus, termed the midblastula transition (MBT) $[10,11]$. In zebrafish the MBT initiates at cycle 10 [12], when the embryo contains 512 cells [13]. In medaka MZT is uncoupled from the midblastula stage, and begins already at the 64 cells stage coinciding with the start of asynchronous cell division [14]. In contrast, a large proportion of the maternal RNA is degraded already at the 2cell stage in mammals $[15,16]$, highlighting the marked species-specific differences in the timing of mRNA degradation and subsequent zygotic genome activation.

The basic composition of maternal RNAs in the oocyte and early embryogenesis has only been assayed in a few teleost species including zebrafish $[17,18]$ and recently Atlantic cod [19]. However, these studies looked at the composition of expressed genes using a microarray. Olsvik [20] characterized the blastula stage in cod, using a sequenced un-normalized cDNA library. This technique has also been applied to study oocytes and early stages of development in mouse, Atlantic halibut and zebrafish $[6,21,22]$. This type of study helps identifying overall abundance, novel transcripts, and splice variants in the transcriptome in contrast to microarray which only determine expression levels of a predefined subset of genes. Aanes [6] and Evsikov [21] did assay the 3'UTR sequence of the assayed maternal RNAs and were able to find regulatory signals conferring stability and function of maternal RNAs. Therefore the aim of this study was to characterize the composition of maternal RNAs in oocytes and early embryos of Atlantic cod, by sequencing 3'UTRs of RNA from unfertilized eggs and embryos of 1-2 cell-, blastula- and gastrula stage (Figure 1). In silico studies focus on transcript- and gene abundance, identity, diversity, ontology, stability and complexity in maternal vs. zygotic developmental stages. This work also focuses on two technical difficulties when analyzing this type of data; (1) the reliability of gene expression profiles obtained from cDNA libraries and (2) the difficulty of using internal reference genes when working with egg and early developmental stages.

\section{Results and discussion}

\section{Methodological considerations; number of sequences}

\section{threshold and external spiking}

Transcriptome sequencing offers the possibility to discover novel expression patterns, high abundance transcripts, sequence motifs and splice variants [6]. In addition transcriptome sequencing measures abundance at a wider scale, as this technique does not get oversaturated. However challenges regarding quality do exist, it is for example crucial for the correct annotation to have a high-quality reference genome. Another aspect of quality is how reliable the expression patterns discovered in libraries really are. Highly expressed genes represent processes that dominate in the given developmental stage, and discovery and measurements of such gene expressions are more likely to be accurate than that of
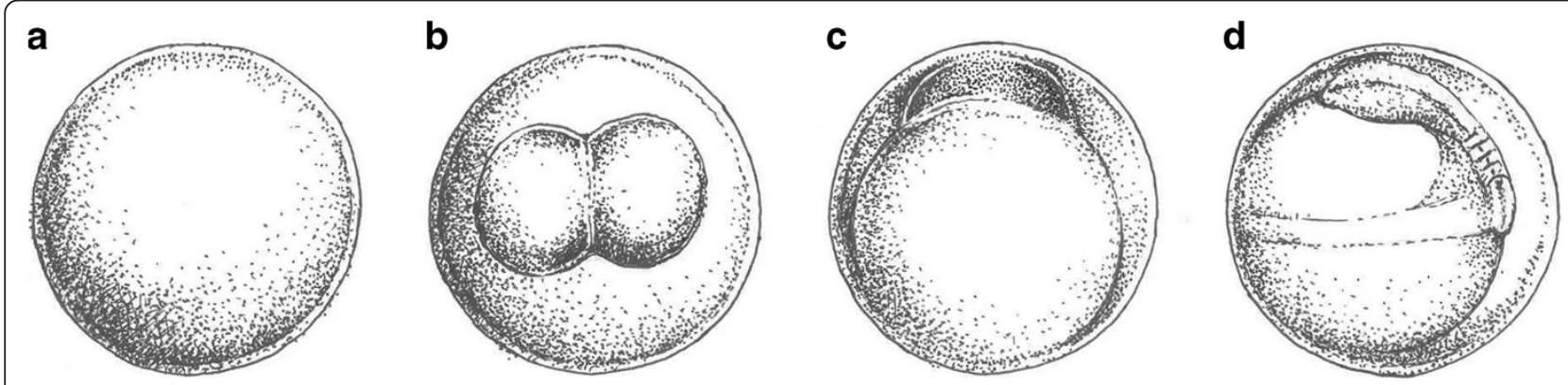

Figure 1 The developmental stages of cod that were studied. Drawing of the developmental stages of Atlantic cod that were used in this study; spawned, unfertilized egg (a), 1-2 cells (b), blastula (c) and gastrula (d). All oocytes referred to in this paper represent mature oocytes e.g. eggs. 
genes that are weakly expressed. Singletons $(n=1)$ are more likely to represent random sequencing or sequnecing errors than transcripts that are sequenced numerous of times for one gene. Likewise, in microarray studies, low number of transcripts causes a large variation in gene expression results [23]. This was also confirmed in this study as we revealed that for genes with few sequences (total $n=1-5$ ) detected in the libraries, the expression profile from oocyte until gastrula could not be reflected in expression profiles measured with quantitative PCR (qPCR) for the same genes (Figure 2). For genes with a higher number $(n=12-61)$ of sequences, their expression profiles corresponded with the ones measured by qPCR (Figure 2). We therefore suggest for further transcriptomic studies to filter data based on analysis of number of transcripts to obtain reliable expression profiles for downstream analyses. A threshold of 9 or more total sequences for each gene was selected to be applied for our dataset, to be able to include only the most reliable data for analysis. Threshold 9 was chosen because it is in the middle of 5 and 12, and using this threshold did not considerably affect number of genes to be excluded for downstream analyses compared to when applying threshold 5. Given that only 1 EST was sequenced for approximately $50 \%$ of the genes in our dataset (data not shown), even a very low cutoff would exclude a high number of genes from the analysis. However some important information may be hidden within genes with low expression, and will therefore be lost by applying an EST number threshold. For example, the zebrafish oocyte possesses a considerable richness of maternally expressed genes of which many may be of importance for embryogenesis [6]. When the current experiment was carried out the cod genome was not yet sequenced. However, using the current genome [24] together with new sequencing technology could significantly increase number of reads analyzed in this study. For example, Aanes recently studied the zebrafish embryonic transcriptome by applying RNA sequencing [6], a method which provides a considerably more precise measurement of transcript abundance due to high number of sequence reads [20-22]. If we were to perform this study again with RNA sequencing, more sequence reads would be obtained and more genes could be included in the analysis as they would be represented by more than only 1 or a few sequenced transcripts.

Also if candidate gene expressions from cDNA libraries are to be verified by qPCR, stable reference genes are essential. When it comes to early embryo tissue like in this study, such stable references are difficult to obtain.

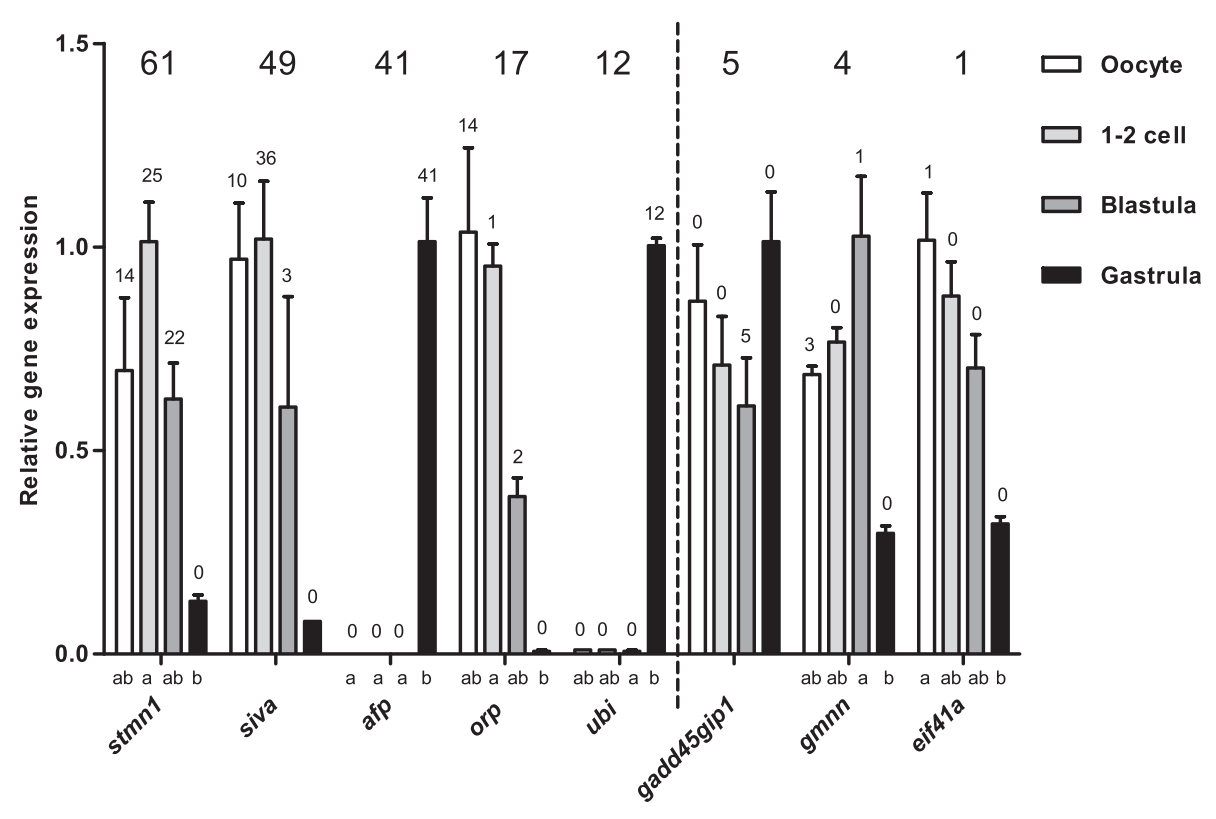

Figure 2 Gene expression profiles measured with number of transcripts in libraries and qPCR. Gene expression levels of stathmin 1 (stmn 1), apoptosis regulatory protein siva (siva), antifreeze protein (afp), oogenesis related protein (orp), ubiquitin (ubi), growth arrest and DNA-damageinducible, gamma interacting protein 1 (gadd45gip 1), geminin (gmnn) and eif41a (x-axis), relative to rabbit alpha hemoglobin (hba) (y-axis). The numbers above each bar represent the number of times the transcript was sequenced in that particular library. The bold number above each gene expression profile represents the total number of times the transcript was sequenced. The vertical dotted line indicates threshold for total $\mathrm{n}$, in further library analysis. Different letters on $\mathrm{x}$ axis represent significantly different mRNA levels between stages for each gene. Genes with no letters on $\mathrm{x}$-axis show no significant difference in gene expression between stages. All data are shown as mean with SEM. N =3. 
For example, neither $\beta$-actin, elongation factor 1 - $\alpha$ (ef1 $\alpha), 18 S$, actin related protein (arp) nor ubiquitin (ubi) showed stable reference gene expression in stages assayed for gene expression [Additional file 1], [25,26]. For this reason we chose not to use any of the reference genes tested, but instead apply a technique (external spiking) where external RNA (rabbit alpha hemoglobin $(h b a))$ is added in equal amounts to each RNA sample [27]. The considerably more stable expression pattern of hba can be seen in [Additional file 1]. We therefore suggest that external spiking may serve as a good alternative to the traditional reference genes previously applied in qPCR, especially when measuring gene expressions in early embryo tissue.

Overall composition of cDNA libraries from oocyte, 1-2 cell, blastula and gastrula stage in Atlantic cod: amount of transcripts and genes, and mitochondrial contribution In order to get an impression of the approximate timing of MZT (and therefore the shift from degrading to activating transcripts) we measured gene expression profiles of candidate genes known from other species to be maternal, zygotic or involved in events taking place at the initiation of MZT [Additional file 2]. Our results together with the findings of Drivenes [19] indicate that the MZT takes place between blastula and gastrula in Atlantic cod, which is also true for zebrafish [12]. Together the cDNA libraries from oocyte, 12 cell, blastula and gastrula stage produced 26162 3'EST sequences, which have been added to GenBank; 6511, 6607, 6506 and 6538 sequences were obtained from oocyte, 1-2 cell, blastula and gastrula libraries, respectively. 22229 sequences (5538, 5875, 5238 and 5578 in oocyte, 1-2 cell, blastula and gastrula, respectively) were mapped to the Atlantic cod genome [24]. 17025 of these sequences hit cod genes with the rules given in material and methods section; they were predicted to encode 2611 genes, of which 2051 (78.6\%) were Ensembl-annotated. 23 genes were pseudogenes, and were therefore removed from most of the analysis. Furthermore as described in methodological considerations, sequences with $\mathrm{n} \leq 8$ were removed from most of the analysis, leaving us with 12764 sequences predicted to be encoded by 257 genes. Compared to similar analyses [20-22], 257 genes is a low number; however these studies have included most transcripts in contrast to the current study. As mentioned, we showed no correlation between qPCR and low copy number of ESTs $(\mathrm{N}<9$, see Figure 2 and discussion first section; methodological considerations), and highly expressed genes $(\mathrm{N}>9)$ are possible to classify as maternal, zygotic, degrading and activating. EST copy number filtering was a necessity to be able to study stability and complexity of dominating transcripts in early embryos of cod.

Strikingly, the overall composition of abundant transcripts obtained from maternal stages (oocyte, 1-2 cell and blastula) contained 45.9-50.6\% mitochondrial transcripts, while at the zygotic stage (gastrula) only $12.2 \%$ of the transcripts were mitochondrial (Figure 3). Less than $5.1 \%$ of all the expressed genes in each developmental stage encoded these numerous mitochondrial transcripts (data not shown). This trend was also evident by the highly expressed mitochondrial genes of Table 1, showing the 20 most abundantly expressed genes when all transcripts from all libraries were included. Likewise it has been reported a high level of mitochondrial transcripts at the 2-cell stage in halibut [22] and in the oocyte of Senegalese sole [28]. High level of mitochondrial transcripts in mature oocytes may be linked to high metabolic need to complete synchronous continuous cell-divisions at early developmental stages, whereas at later stages the energy metabolism is more localized to target areas in specific development. It has even been suggested that a major part of maternal RNAs in egg-laying organisms lack specificity and only provides supplemental nutrition [29]. However a proportion of the maternal RNAs are essential for normal development in fish, as several studies report abnormal embryo development when mRNA translation is inhibited [30]. Also several processes in zebrafish morphogenesis, most notably brain

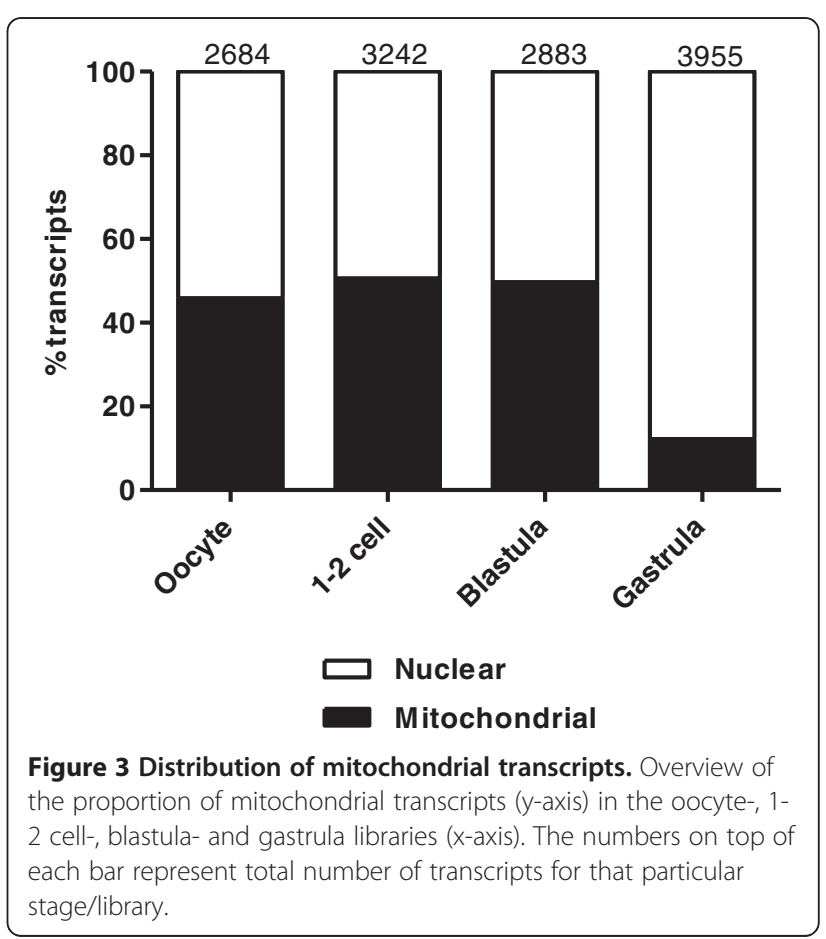


Table 1 The 20 most abundant transcripts

\begin{tabular}{|c|c|c|c|c|c|}
\hline Gene & Total & Oocyte & $1-2$ cell & Blastula & Gastrula \\
\hline \multicolumn{6}{|l|}{ Mitochondrial genes } \\
\hline Cytochrome c oxidase subunit II & 3418 & 910 & 1293 & 881 & 334 \\
\hline Cytochrome B & 563 & 137 & 114 & 263 & 49 \\
\hline Cytochrome c oxidase subunit I & 353 & 90 & 110 & 119 & 34 \\
\hline ATP synthase FO subunit 8 & 176 & 36 & 45 & 84 & 11 \\
\hline ATP synthase FO subunit 6 & 144 & 32 & 45 & 50 & 17 \\
\hline \multicolumn{6}{|l|}{ Nuclear genes } \\
\hline H2A Histone family, member $V$ & 463 & 94 & 208 & 82 & 79 \\
\hline Tetraspanin 3 & 185 & 3 & 20 & 159 & 3 \\
\hline Small nuclear ribonucleoprotein polypeptide $E$ & 133 & 25 & 34 & 7 & 67 \\
\hline Ribosomal protein $\$ 20$ & 128 & 2 & 1 & 2 & 123 \\
\hline Ribosomal protein $\mathrm{S12}$ & 111 & 7 & 1 & 1 & 102 \\
\hline Ribosomal protein $\mathbf{S} 23$ & 106 & 0 & 0 & 0 & 106 \\
\hline Ribosomal protein L34 & 103 & 4 & 4 & 16 & 79 \\
\hline CDKN2A interacting protein N-terminal like & 103 & 27 & 28 & 19 & 29 \\
\hline COX17 cytochrome c oxidase assembly homolog & 101 & 60 & 28 & 13 & 0 \\
\hline Unknown & 97 & 46 & 48 & 2 & 1 \\
\hline Small nuclear ribonucleoprotein D3 polypeptide 18kDa & 95 & 16 & 36 & 32 & 11 \\
\hline Small nuclear ribonucleoprotein polypeptide $F$ & 84 & 10 & 8 & 63 & 3 \\
\hline Mago-nashi homolog $B$ & 78 & 10 & 25 & 39 & 4 \\
\hline Unknown & 78 & 0 & 0 & 0 & 78 \\
\hline Unknown & 74 & 2 & 0 & 3 & 69 \\
\hline
\end{tabular}

Gene names and their total number of transcripts in oocyte, 1-2 cell, blastula and gastrula are shown.

formation, fail to occur normally when normal degradation of maternal RNA is disturbed [31].

\section{Nuclear transcripts and expressed genes: distribution and gene ontologies}

To facilitate analysis of expressed genes from the genome, mitochondrial transcripts (4786, encoded by 10 genes) were excluded. What remained were the nuclear transcripts (7978, encoded by 247 genes). A significant feature of the gastrula nuclear transcriptome was a high presence of ribosomal transcripts (50.6\%) compared to the earlier stages $(2.5-4.6 \%$, Figure $4 a)$. This increase in transcript abundance was not a consequence from many additional genes being expressed in the gastrula stage, as the number of genes encoding the ribosomal transcripts only increased from $6.7-13.1 \%$ in the maternal libraries to $19.7 \%$ in the gastrula library (Figure $4 \mathrm{~b}$ ). However, some of the ribosomal transcripts were uniquely found in the gastrula library (Table 2). A similar pattern of ribosomal transcripts has previously been found in zebrafish [17] and halibut [22]. The high presence of ribosomal transcripts in gastrula is most likely due to major onset of transcription since ribosomal proteins are required for the production of ribosomes at the site for transcription.

Most nuclear genes (79.4\%) were expressed in more than one developmental stage, and $51.8 \%$ (128) of the genes were expressed in all four stages. The most highly expressed genes (see Table 1) present in all libraries were histone $H 2 A$ family member $V$ followed by tetraspanin 3, which are involved in general processes like structuring of chromosomal fibres and signal transduction in cell development, activation, growth and motility. $12.1 \%$ (30) of the nuclear genes were expressed exclusively in maternal stages (oocyte only or oocyte and one or two of the next developmental stages), and represented a diverse group (Table 3). However among the ones with the highest numbers of transcripts in this category, we found common genes (like COX17, stathmin and cyclins) involved in processes like energy metabolism and cell cycle, which are features that characterize early embryonic development. Other studies [6,22,32] report on a higher number of strictly maternal genes than 30 , however as mentioned many genes were excluded in this study due to their low number of sequenced ESTs. Since the cutoff of $\mathrm{N}=9$ may have excluded many lower 


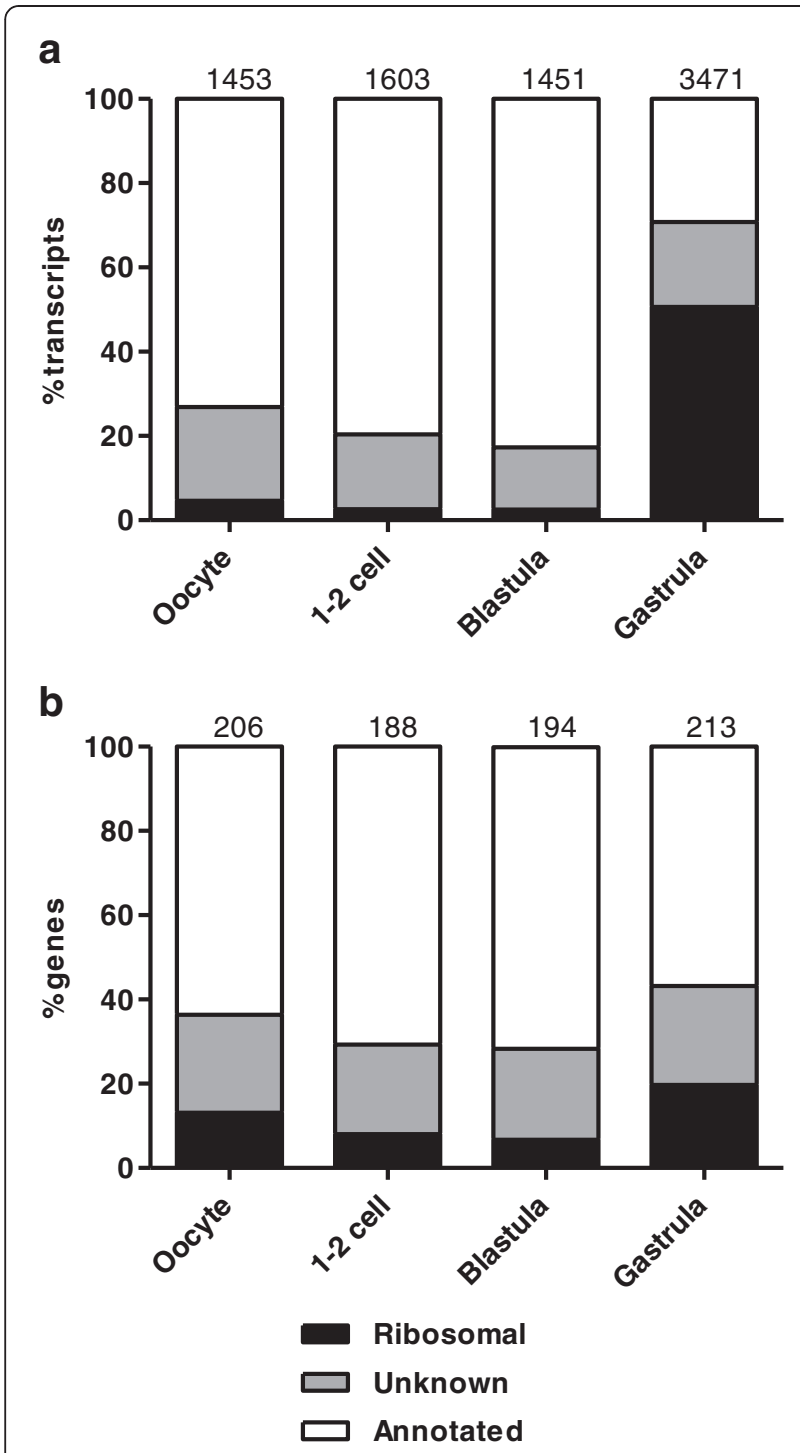

Figure 4 Distribution of nuclear transcripts and the genes encoding them. Overview of the distribution ( $y$-axis) of nuclear transcripts (a) and the genes encoding them (b) in the oocyte-, 1-2 cell-, blastula- and gastrula libraries (x-axis). The numbers on top of each bar represent total number of transcripts or genes for that particular stage/library.

expressed but important maternal genes from downstream analysis all sequenced genes were added to GenBank, leaving them available for future studies of for example egg viability.

We also checked how the nuclear transcripts were distributed when including all nuclear genes (2575) without any threshold for number of transcripts. In this dataset a large proportion (56.5\%) of the genes had only 1 transcript. Consequently, the genes expressed exclusively in maternal and gastrula stages showed an increase in their proportions (12.1-31.9\% and $6.9-13 \%$, respectively). The proportion of genes expressed in all developmental stages decreased markedly from 51.8 to $6.5 \%$ [Additional file 3]. It is therefore clear that the use of a threshold for number of transcripts makes a difference for describing gene expression patterns.

Functional profiles of the most common nuclear transcripts in oocyte, 1-2 cell, blastula and gastrula (obtained from the use of gene ontology (GO)-terms) revealed that both within cellular component, molecular function and biological process many of the transcripts did not change much in their abundance over time (data not shown). However some differences could be observed between maternal and zygotic stages [Additional file 4]. An increase in proportion of transcripts that were part of macromolecular complexes from maternal to zygotic developmental stage possibly reflects specification of cell types which requires more complex molecules as the embryo enters the zygotic stage. At the molecular function level, a pronounced increase of transcript amount from maternal to zygotic stage was evident for structural molecule activity, reflecting a shift towards specification of cell function. Several biological processes including cellular component organization or biogenesis, multicellular organismal process and developmental process showed a marked shift between maternal and zygotic stage, with increase in transcript proportion in gastrula. Taken together, these changes reflect more specialized and complex processes developing after MZT in cod, as would be expected since gastrula is a developmental stage where intricate processes like germ layer formation takes place (reviewed in [33]).

\section{3'UTR structure: isoforms, length and motifs}

Based on manual annotation, 3'UTR length was predicted for all sequences with stop codon and poly-A tail (in total 191 genes). To be able to study the gene expression dynamics over time from a maternal to a zygotic embryo, genes (when possible) were strictly classified as having degrading, stable or activating transcripts. In order to be termed degrading, minimum $95 \%$ of the transcripts had to be located in maternal stages (oocyte until blastula). In order to be termed activating, minimum $95 \%$ of the transcripts had to be present in blastula and gastrula. Transcripts present in all 4 stages, with a distribution of minimum $10 \%$ and maximum $40 \%$ in one stage were termed stable. Applying this classification gave 35,26 and 39 genes with degrading, stable and activating expression profiles, respectively. 91 genes could not be classified according to these specifications. To ensure reliable results, the following analyses on 3'UTR structure were also performed when applying less strict specifications [Additional file 5].

Totally 73 nuclear genes (29.6\%) expressed more than one 3'UTR isoform. Among genes with degrading and stable transcripts a relatively high amount (45.7 and 
Table 2 The 17 transcripts present in the gastrula library only

\begin{tabular}{|c|c|c|c|c|c|}
\hline Gene & Total & Oocyte & $1-2$ cell & Blastula & Gastrula \\
\hline \multicolumn{6}{|l|}{ Nuclear genes } \\
\hline Ribosomal protein $\$ 23$ & 106 & 0 & 0 & 0 & 106 \\
\hline Unknown & 78 & 0 & 0 & 0 & 78 \\
\hline Ribosomal protein L27a & 58 & 0 & 0 & 0 & 58 \\
\hline Ribosomal protein L28 & 54 & 0 & 0 & 0 & 54 \\
\hline Unknown & 50 & 0 & 0 & 0 & 50 \\
\hline Ribosomal protein L18a & 48 & 0 & 0 & 0 & 48 \\
\hline Ribosomal protein L24 & 48 & 0 & 0 & 0 & 48 \\
\hline ribosomal protein $\$ 27$ & 48 & 0 & 0 & 0 & 48 \\
\hline Ribosomal protein $S 19$ & 46 & 0 & 0 & 0 & 46 \\
\hline Unknown & 41 & 0 & 0 & 0 & 41 \\
\hline Unknown & 40 & 0 & 0 & 0 & 40 \\
\hline Ribosomal protein L31 & 36 & 0 & 0 & 0 & 36 \\
\hline Ribosomal protein S7 & 30 & 0 & 0 & 0 & 30 \\
\hline Ribosomal protein, large, P2 & 26 & 0 & 0 & 0 & 26 \\
\hline Ribosomal protein, large, P1 & 14 & 0 & 0 & 0 & 14 \\
\hline Ubiquitin A-52 residue ribosomal protein fusion product 1 & 12 & 0 & 0 & 0 & 12 \\
\hline Small nucleolar RNA, C/D box 68 & 9 & 0 & 0 & 0 & 9 \\
\hline
\end{tabular}

Gene names and their total number of transcripts in oocyte, 1-2 cell, blastula and gastrula are shown.

Table 3 The 20 most abundant transcripts found in maternal libraries only

\begin{tabular}{|c|c|c|c|c|c|}
\hline Gene & Total & Oocyte & 1-2 cell & Blastula & Gastrula \\
\hline \multicolumn{6}{|l|}{ Nuclear genes } \\
\hline COX17 Cytochrome c oxidase assembly homolog & 101 & 60 & 28 & 13 & 0 \\
\hline Stathmin 1 & 61 & 14 & 25 & 22 & 0 \\
\hline Adenylosuccinate synthase like 1 & 49 & 10 & 36 & 3 & 0 \\
\hline S100 calcium binding protein A1 & 41 & 9 & 26 & 6 & 0 \\
\hline THAP domain containing 4 & 34 & 10 & 16 & 8 & 0 \\
\hline Unknown & 25 & 7 & 0 & 18 & 0 \\
\hline Uncharacterized protein C14orf119 & 24 & 0 & 1 & 23 & 0 \\
\hline Unknown & 20 & 6 & 9 & 5 & 0 \\
\hline Claudin 4 & 20 & 9 & 6 & 5 & 0 \\
\hline Unknown & 20 & 8 & 4 & 8 & 0 \\
\hline LSM12 homolog & 19 & 3 & 15 & 1 & 0 \\
\hline UPF0139 membrane protein C19orf56 & 17 & 2 & 11 & 4 & 0 \\
\hline Topoisomerase (DNA) I & 17 & 10 & 5 & 2 & 0 \\
\hline Unknown & 17 & 7 & 4 & 6 & 0 \\
\hline Unknown & 17 & 14 & 1 & 2 & 0 \\
\hline Cyclin A1 & 15 & 2 & 6 & 7 & 0 \\
\hline Protein (peptidylprolyl cis/trans isomerase) NIMA-interacting, 4 (parvulin) & 15 & 5 & 2 & 8 & 0 \\
\hline Cyclin A2 & 15 & 3 & 1 & 11 & 0 \\
\hline H1 histone family, member $O$, oocyte-specific & 14 & 5 & 3 & 6 & 0 \\
\hline Unknown & 12 & 4 & 7 & 1 & 0 \\
\hline
\end{tabular}

Gene names and their total number of transcripts in oocyte, 1-2 cell, blastula and gastrula are shown. 


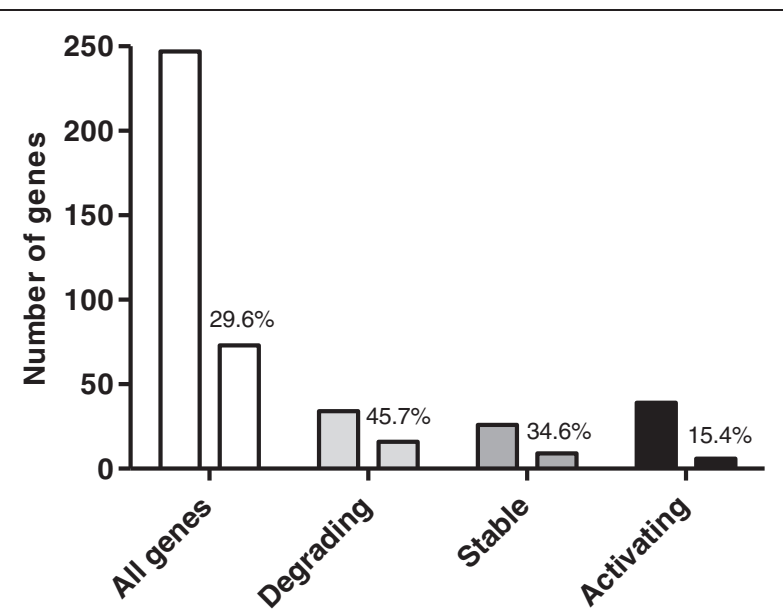

Figure 5 3'UTR isoforms. Overview of number of genes with $3^{\prime} U T R$ isoforms ( $y$-axis) within the whole dataset, and within genes with degrading, stable and activating transcripts ( $x$-axis). The bar to the left within each category represents the total number of genes for that category, and the bar to the right represents the corresponding number of genes with 3'UTR isoforms. Percentages of genes with $3^{\prime} U T R$ isoforms within each group are indicated by the number on top of the bars.

34.6\%, respecively) displayed 3'UTR isoforms (Figure 5). Alternatively spliced transcripts are common in early embryos in other species, for example in zebrafish where it has been shown $50-60 \%$ alternative splicing of transcripts [6]. Also in mouse embryos a significant proportion of alternatively spliced transcripts have been found [34], and in this context it was suggested that alternative splicing is of importance in the regulation of development. Activating genes of cod had a far less degree of 3'UTR isoforms (15.4\%, Figure 5). This may be an indication that alternative splicing is a less important

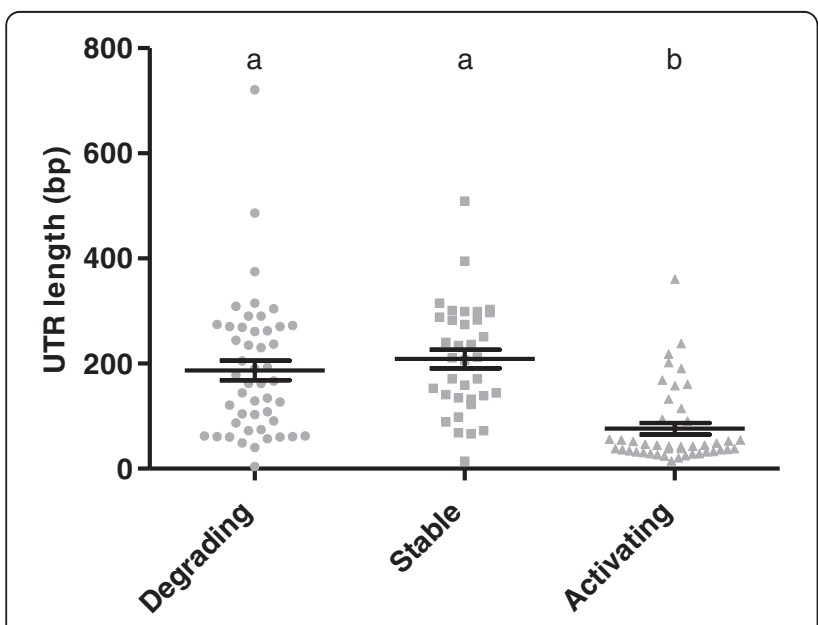

Figure 6 3'UTR length. 3'UTR-lengths of degrading, stable and activating transcripts. Different letters represent significant difference in $3^{\prime} U T R$ length. All data are shown as mean with SEM. $N=48,35$ and 45 for degrading, stable and activating transcripts, respectively. regulatory mechanism for genes that are more active in early zygotic stages, than for genes that are more active in maternal stages.

Mean 3'UTR length (when including all isoforms) in degrading $(\mathrm{n}=48)$, stable $(\mathrm{n}=35)$ and activating $(\mathrm{n}=45)$ transcripts was 187.1, 208.8 and 76 bp, respectively (Figure 6). Activating transcripts had significantly $(\mathrm{p}<$ 0.0001) shorter 3'UTR length than degrading and stable ones. A higher proportion of long maternal 3'UTRs have previously been found across the animal kingdom [29] associated with lower turnover-rate of RNAs [35]. Our findings suggest that also in cod, transcripts from maternally active genes have longer 3' UTRs. The shorter 3' UTRs of the activating transcripts may also be explained by the fact that many of them were ribosomal (data not shown); such transcripts have been shown to contain short 3'UTRs [36]. Excluding ribosomal genes would lead to a small dataset. Consequently, we applied less strict classification criteria for degrading, stable and activating transcripts and found that also non-ribosomal activating transcripts have significantly shorter 3'UTRs [Additional file 5].

Although not statistically proved in this study, stable transcripts appeared to have the longest 3'UTRs (Figure 6). This corresponds to the suggestion that more stable RNAs have longer UTRs [37]. A strong exponential correlation has been found between 3'UTR length and morphological complexity (number of cell types in the organism) [38]. Increased regulatory complexity in long 3'UTRs may be a result of more miRNA binding sites. Furthermore, additional polyadenylation signals may produce transcript isoforms with several combinations of miRNA binding sites, which adds even more complexity [39]. It was observed an enrichment of 3'UTR isoforms in degrading and stable transcripts (abundant in the maternal stages) compared to activating ones (abundant in zygotic stage). This result suggests a more complex post-transcriptional regulation in the maternal stages since transcriptional regulation cannot be applied to control developmental processes prior to MZT.

The apparent complex features of transcripts that were abundant in early developmental stages of cod were further investigated by searching for motifs in the 3'UTRs of degrading, stable and activating transcripts. Using Multiple Em for Motif Elicitation (MEME) [40] the presence of the polyadenylation motif AATAAA was indicated. Manual inspection of the sequences revealed that AATAAA (the exact motif) was present at an increasing manner from degrading (68.8\%), through stable $(82.9 \%)$ and to activating (95.6\%) transcripts (Figure 7a). AATAAA is essential for cytoplasmic polyadenylation to take place $[41,42]$; that is, cleavage followed by adding of a poly-A tail to the 3' end of the mRNA which then activates translation. Therefore polyadenylation is a key process in regulation of translation (for recent reviews see $[43,44])$, and thus serves as an important step in 


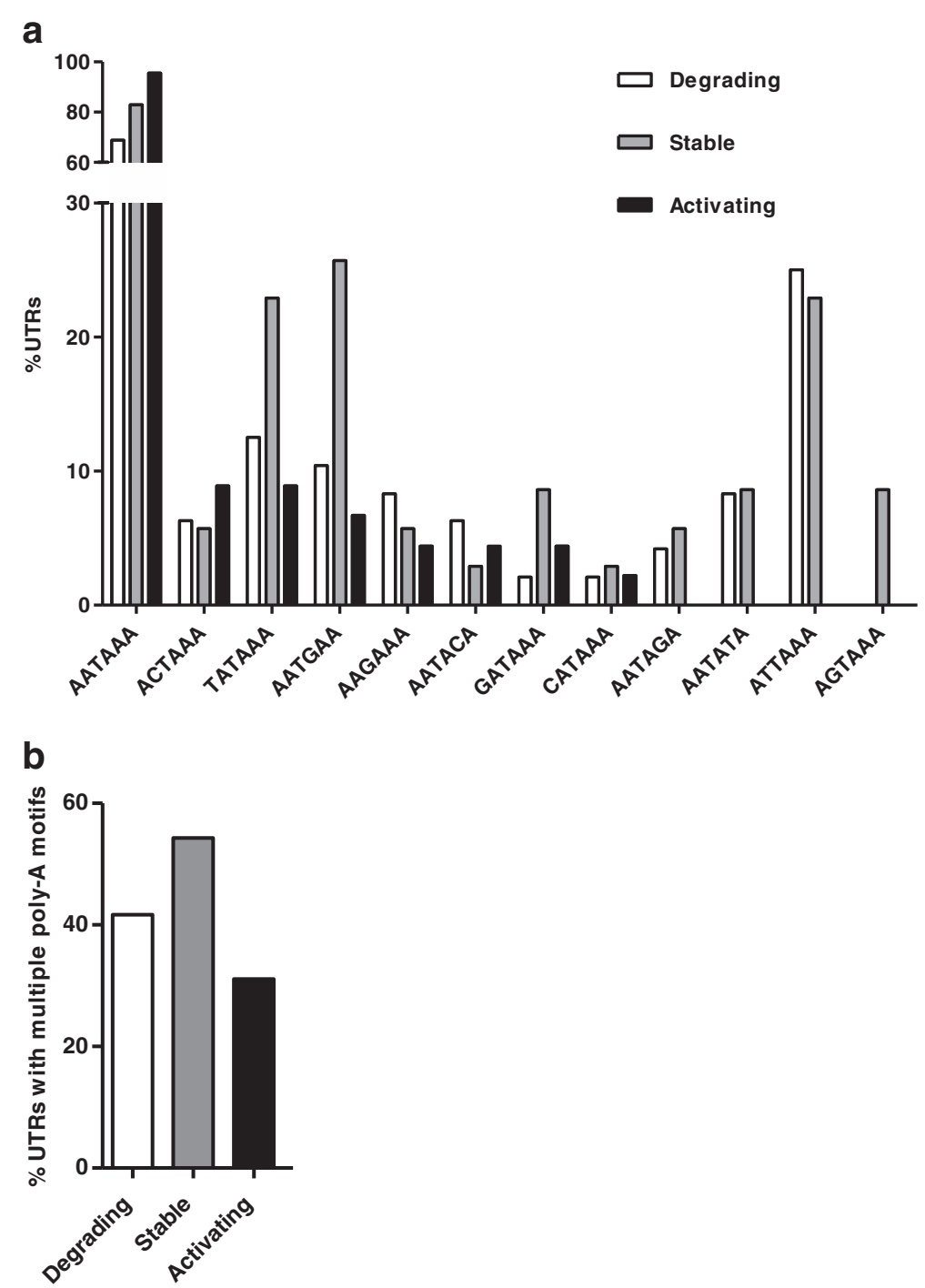

Figure 7 Polyadenylation motifs. Proportion (\%) of degrading, stable and activating transcripts that contain different polyadenylation motifs (AATAAA, ATTAAA, AGTAAA, TATAAA, CATAAA, GATAAA, AATATA, AATACA, AATAGA, ACTAAA, AAGAAA and AATGAA) (a) and more than one of the motifs shown in a) (b). $N=48,35$ and 45 for degrading, stable and activating transcripts, respectively.

post-transcriptional regulation in maternal stage embryos. Also, it was recently found that cytoplasmic polyadenylation of maternal RNAs prior to MBT is essential for normal morphogenesis post-MBT in zebrafish [6]. It is known that AATAAA is found in nearly all known mRNAs, and that it is highly conserved. Our finding that 31.2 and $17.1 \%$ of degrading and stable transcripts (with known 3'UTR length) did not contain AATAAA may be explained by the possibility of transcripts to contain alternative polyadenylation motifs, where AATAAA have been slightly modified (reviewed in [43]). Therefore, we investigated the presence of 11 other putative alternative polyadenylation motifs [45]; for each sequence we observed which motifs were present, and if there was more than one motif (Figure 7).
3 motifs (ATTAAA, AATATA and AATAGA) were found exclusively in degrading and stable transcripts, and AGTAAA was present only in stable transcripts. None of the motifs were unique for activating transcripts, and most of the motifs were present at the lowest rate in this group of transcripts (Figure 7a). Also, degrading and especially stable transcripts had a higher prevalence (41.7 and $54.3 \%$, respectively) of multiple motifs (more than one of the motifs studied) than activating ones (31.1\%, Figure $7 \mathrm{~b})$. A higher degree (diversity and quantity) of putative alternative polyadenylation motifs in maternal degrading and stable transcripts suggests that these transcripts may apply alternative polyadenylation more frequently than activating transcripts. Polyadenylation at different sites produces different 
variants of the 3'UTR, which contributes to a more complex transcriptome [46].

\section{Conclusions}

This study shows that scarce transcripts represent a significant bias in transcriptomic assessments of sequenced libraries, and suggests for future studies to compare number of transcripts and qPCR analysis to set a threshold for the transcript abundance that reflects reliable expression profiles. This study also shows a solution for dealing with the problem of internal variation in housekeeping genes when analyzing relative expression over time in fish embryos. By adding an external normalization gene the problem with housekeeping gene variation was avoided [27].

In maternal stages (oocyte to blastula), mitochondrial genes encoded $45.9-50.6 \%$ of the transcripts, reflecting a high energy demand in embryos up until MZT. The zygotic nuclear transcriptome had a high presence of ribosomal transcripts (50.6\%), reflecting a major onset of transcription at this stage. Gene ontology terms reflect a more complex and specialized gastrula compared to maternal developmental stages. Degrading and stable transcripts have longer 3'UTRs than the ones that increased in abundance after MZT. Furthermore, this group of transcripts has more (diversity and amount) of the alternative polyadenylation motifs studied, as well as a higher number of 3'UTR isoforms. Together this indicates a more complex post-transcriptional regulation for genes that are highly active in maternal stages compared to that of genes that are more active in the zygotic embryo of cod.

In summary, this study describes in detail and for the first time, the overall level and composition of common maternal RNAs in the mature cod egg and early stages of embryogenesis, and reveals a picture of the fluctuations in the high abundance transcripts from egg to maternal stages and onwards to onset of zygotic transcription. This characterization of the maternal transcriptome in Atlantic cod (Gadus Morhua L.) will be helpful in further studies with the aim to elucidate the relationship between maternal RNAs and offspring viability in this species.

\section{Methods}

\section{Egg and embryo collection}

Eggs and sperm from Atlantic cod were obtained from Parisvatnet Research station, Institute of Marine Research, Øygarden, Norway in April 2009. Eggs were manually stripped from one female and sperm was collected from one male. Before freezing of unfertilized eggs, egg fluid was carefully aspirated and subsequently eggs were flash frozen liquid nitrogen. Remaining eggs were fertilized with the collected sperm and incubated at $7^{\circ} \mathrm{C}$ until they reached 1-2 cells, blastula and gastrula stages (Figure 1), embryos were staged according to Hall [47]. At sampling, staged embryos were collected and excess water was aspirated off before embryos were flash-frozen on liquid nitrogen. All collected samples were stored at $-80^{\circ} \mathrm{C}$ until RNA isolation was initiated. All egg and embryo samplings were done according to guidelines approved by the Norwegian Animal Research Authority (NARA).

\section{cDNA library construction}

From eggs and each developmental stage, total RNA was isolated using iPrep $^{\mathrm{Tm}}$ Trizol $^{\circledR}$ Plus RNA Kit (Invitrogen, Carlsbad, CA, USA). The quality of RNA showed RIN values above 9.5 for all samples used (Bioanalyzer 2100, Agilent, Santa Clara CA, United States). cDNA libraries were constructed from $1.0 \mu \mathrm{g}$ of RNA from each sample using Creator SMART cDNA Library Construction Kit (Clontech Laboratories, Inc., Mountain View, CA, USA). The cDNA was size-selected for 500bp according to Evsikov [21]. Transformation of the ligation mix was performed using the DH5 $\alpha$ MAX competent cells (Invitrogen, Carlsbad, CA, USA). The titers of libraries used were for oocytes $7,7 \times 10^{5}$, 1 -2 cell stage $4,7 \times 10^{5}$, blastula $1,5 \times 10^{6}$ and gastrula $1,4 \times 10^{6}$ clones per $\mu \mathrm{l}$ of ligation mix. The clones were grown on robot plates (Nalgene Nunc International, Rochester, NY, USA) filled with Luria-Bertani (LB) agar and chloramphenicol $(30 \mathrm{mg} / \mathrm{L})$. Positive clones were randomly selected by automated picking robots and transfered to 384-well plates containing HMFM freezing media. Culturing was performed for $16 \mathrm{~h}$ at $37^{\circ} \mathrm{C}$ without agitation. For isolation and purification of plasmid DNA 384-deepwell plates containing $190 \mu \mathrm{l} 2 \mathrm{YT}$ media and $30 \mathrm{mg} / \mathrm{L}$ chloramphenicol were inoculated from the freezing stocks. Clones were grown for $16-18 \mathrm{~h}$ at $1100 \mathrm{rpm}$ and $37^{\circ} \mathrm{C}$. Isolation and purification of plasmids was done by an automated system, applying alkaline lysis followed by size selective DNA precipitation in PEG/2-Propanol [48]. Quantified plasmids (UV photometry) were sequenced using T7 primers following the BigDye version 3.1 protocol and capillary gelelectrophoresis by an ABI 3730xl system (Applied Biosystems Inc., Foster City, Ca, USA) at Max Planck Institute for Molecular Genetics, Berlin, Germany.

\section{Bioinformatical analysis of raw data}

Sequence trace files from each library were processed employing the Phred base-calling algorithm [49,50]. Quality trimming and removal of contaminating vector sequences were performed using cross match and RBR [51] with the Uinivec filtering database from the National Center for Biotechnology Information (NCBI). Clustering and assembly were carried out using the TIGR Gene Indices Clustering tools (TGICL) [52]. Sequences for the libraries were added to GenBank; oocyte library [GenBank: JK777860-JK784370], 1-2 cell 
Table 4 Gene short names, gene/EST ID and PCR primer sequences (5'-3')

\begin{tabular}{|c|c|c|c|}
\hline Gene & Gene ID & $5^{\prime}-3^{\prime}$ forward primer sequence & $5^{\prime}-3^{\prime}$ reverse primer sequence \\
\hline hba & NM_001082389.2 & GCAGCCACGGTGGCGAGTAT & GTGGGACAGGAGCTTGAAAT \\
\hline eif4la & ENSGMOG00000012412 & GACGATTGAGTCGATAGTGAATGC & CGCCCACCTGTTCTGTAAGG \\
\hline$t b p$ & ENSGMOG00000012435 & CACAGCTGCAGAACATTGTATCAA & TGACGGCCGCAAAACG \\
\hline$t$ & ENSGMOG00000017391 & CAACGAGATGATCGTCACCA & TGGCTGCTGATCATCTTCTG \\
\hline orp & $J K 781166.1$ & GCTTCGGCTCCTIITTATTIITI & CCACTTGTTGTTCCGCAGAGT \\
\hline gmnn & ENSGMOG00000008149 & GATGGTATCTCAAATGAAGCCTATGA & CGCTCGTCTGCCACTTCTTT \\
\hline stmn1 & ENSGMOG00000005322 & GAAACTATTGGAGATATTCAGGTTAAGGA & GCAGGAGCAGCCAGAATCAC \\
\hline siva & JK777503.1 & GAAGCACAGCCTTCTCAACCA & CCAATGAGCGTTGTCCCTT \\
\hline gadd45gip 1 & ENSGMOG00000012967 & CCGCTGAAACTGAACCTCAAG & GCCATTCGGGCGTCTTCT \\
\hline afp & ENSGMOG00000002484 & GAGCTGATGGCGACTGTTCA & CCTCCCGTCCTCGATGATG \\
\hline
\end{tabular}

When possible, sequences are listed with an Ensembl gene ID. Otherwise the sequences are listed with GenBank EST ID (orp and siva) or mRNA ID (hba).

library [GenBank: JK771253-JK777859], blastula library [GenBank: JK758209-JK764714] and gastrula library [GenBank: JK764715-JK771252], respectively.

Clustered sequences were assembled into contigs (Fasta sequences are given in [Additional file 6]) which were further annotated with Ensembl predicted genes [53] by mapping the contigs to the Atlantic cod genome [24] with a threshold above $75 \%$ identity BLAT hit against a genome scaffold in a gene or within $2000 \mathrm{bp}$ downstream of a gene. Sequences that passed the following rules were included in further analysis: 1) above $85 \%$ identity BLAT hit against a genome mapped EST-contig, or 2) above $75 \%$ identity BLAT hit against a genome scaffold in a gene or within $2000 \mathrm{bp}$ downstream of a gene. The mapping of the contigs can be seen in [Additional file 7].

Functional profiles of transcripts were constructed by applying GO-terms to group the transcripts [54]. The Ensembl genes were GO-annotated using BLAST against SwissProt and UniRef90 and annotation files from [55]. BLAST and GO files for SwissProt and UniRef90 that are constructed for Ensembl-annotated genome assembly can be seen in [Additional file 8] and [Additional file 9], respectively.

\section{Quantitative PCR}

Total RNA was extracted by applying RNeasy ${ }^{\circledR}$ Mini Kit (QIAGEN, Oslo, Norway), and genomic DNA was removed by using Turbo DNA-free ${ }^{\mathrm{TM}}$ Kit (Ambion, Austin, Texas, USA), according to the manufacturers instruction. Additionally, all samples were precipitated and redisolved in ddH20 after DNAse treatment. A NanoDrop $^{\circledR}$ NP-1000 spectrophotometer (NanoDrop technologies, Wilmington, DE, USA) was used to measure the quantity and quality of the RNA samples. Samples with a $260 / 280 \mathrm{~nm}$ absorbance ratio outside the range 1.8-2.1 were excluded for further analysis. $1 \mathrm{pg}$ of rabbit hba mRNA (SIGMA; Norway) was added to each RNA sample before cDNA synthesis (spiking). cDNA was produced using Superscript VILO cDNA synthesis (Invitrogen, Carlsbad, Germany). All primers used for amplification and detection of genes were designed applying the software Primer Express 3.0 (Applied Biosystems, Foster city, CA, USA), and are listed in Table 4 together with hba-primers [27]. Quantitative PCR (qPCR) was performed on an SDS 7900HT Fast Real-Time PCR system (Applied Biosystems, Oslo, Norway) system using SYBR ${ }^{\circledR}$ green PCR Master Mix (Applied Biosystems, Foster city, CA, USA), and the thermal cycling conditions were: $50^{\circ} \mathrm{C}$ for $2 \mathrm{~min}$ followed by $98^{\circ} \mathrm{C}$ for $10 \mathrm{~min}$, and 40 cycles of $95^{\circ}$ $\mathrm{C}$ for $15 \mathrm{~s}$ followed by $60^{\circ} \mathrm{C}$ for $1 \mathrm{~min}$. PCR efficiencies were verified to be equal between target and calibrator genes (Standard-curve method using 250, 125, 62.5, 31.25 and $15.625 \mathrm{ng}$ RNA). Melting curve analysis was performed to verify presence of only one PCR product. $62.5 \mathrm{ng}$ RNA was used to produce cDNA used for downstream analysis of relative abundance of transcript. For each PCR plate, notemplate controls were run for each gene. The relative gene expression level was calculated using the Comparative $\mathrm{Ct}$ method (Applied Biosystems). All data are normalized to $h b a$ mRNA (spike), and the data for each gene are calibrated to its lowest mean $\Delta \mathrm{Ct}$.

\section{Statistical analyses}

All data to be analyzed for significant differences were initially tested for Gaussian distribution by applying a D'Agostino-Pearson normality (omnibus K2) test. All mRNA levels quantified by qPCR had too few replicates $(n=3)$ for each developmental stage in order for the test to reveal normality or not. Therefore a non-parametric Kruskal-Wallis test was applied to reveal if the genes were differentially expressed in one or more of the developmental stages. Dunn's multiple comparison posttest was used to detect at which developmental stages there were differences. Furthermore there was no evidence for Gaussian distribution in the datasets for 3' 
UTR length analysis, including when they were converted to $\log$ values. Therefore a non-parametric Kruskal-Wallis test was also applied here to calculate if there were any differences in UTR length between different groups of transcripts. Dunn's post test was applied to reveal which groups differed from each other. The statistical tests were performed using GraphPad Prism 5.04 (GraphPad Software Inc., La Jolla, CA92037, USA). A $\mathrm{p}$-value of $\leq 0.05$ indicates significant difference.

\section{Additional files}

Additional file 1: Gene expression of reference genes in oocyte, 1-2 cell, blastula and gastrula stage in cod. mRNA levels are shown as cycle threshold (Ct)-values when 250 ng RNA was used for cDNA synthesis. All data are shown as mean with SEM. $N=2$.

Additional file 2: Gene expression levels of candidate genes to reveal timing of midblastula transition in cod. mRNA levels of 3 candidate genes were measured in oocyte, 1-2 cell, blastula and gastrula stage. mRNA levels are relative to $h b a$. Bars with different letters represent significant different mRNA levels for each gene. All data are shown as mean with SEM. $\mathrm{N}=3$. The maternal candidate chosen was the eukaryotic translation initiation factor $4 E$ (eif4e) in which the $1 \mathrm{~b}$ variant is found in oocyte and early embryo only in mouse (eif4Eloo, eif4lb; [21]) and zebrafish [55]. Syntenic analysis in cod did not reveal eif41b, suggesting that this gene has been lost in this species (Data not shown, [27]). We measured eif4la, and mRNA levels significantly decreased from 1-2 cell stage to gastrula. In contrast, Robalino [57] detected a constant level of eif41a in oocyte and early embryo. eif41a is involved in recruiting cytoplasmic mRNA and initiation translation [58], and higher levels of eif4la generally correlate with increased protein synthesis and cell growth [59]. To indicate MZT, the TATA box binding protein (tbp) was selected. During early cleavage maternal stores of tbp are translated and by MBT the protein contribute to transcription initiation in Xenopus [60] and zebrafish [61]. tbp is also involved in degradation of maternal mRNAs [62], another main feature of MZT. In accordance with this, we detected a gradual decrease in tbp mRNA levels from oocyte until blastula. At gastrulation zygotic gene expression is presumably active, and one early zygotic gene in zebrafish is no tail (t), which is expressed in nuclei of the germ ring of the late blastula and early gastrula $[63,64]$. Likewise we did not detect expression of this gene until gastrula, where it was highly expressed.

Additional file 3: Distribution of nuclear genes with and without transcript number threshold. The bar to the left represents the proportion of nuclear genes that were expressed exclusively in maternal stages, gastrula or in all four stages, when analyzing the dataset with a transcript number threshold $(n>8)$. The bar to the right represents the dataset when no threshold is applied. Total number of genes in the datasets (100\%) is indicated on top of each bar.

Additional file 4: Functional profile of transcripts that showed a difference in abundance between maternal and zygotic stages. Three levels of function (parent ontologies) are shown: cellular component, molecular function and biological process. The number on top of each bar represents the total number of transcripts in that stage, which could be coupled to the parent ontology (percentages are therefore calculated from these numbers as 100\%). Each transcript may have multiple gene ontology annotations. Regarding cellular component 115 (oocyte), 122 (1-2 cell), 160 (blastula) and 80 (gastrula) transcripts did not have an annotation. The respective numbers for molecular function were 219, 250, 344 and 179, and for biological process they were 211, 251, 350 and 133. Macromol. comp. = macromolecular complex. Str. mol. act. $=$ structural molecule activity. Cell. comp. org. $=$ cellular component organization or biogenesis. Multicell. org. pr. = multicellular organismal process. Dev. pr. = developmental process.
Additional file 5: Results from repeated 3'UTR structure analyses, with less strict criteria for classification and excluding all ribosomal genes. Results from repeated analyses on $3^{\prime} U T R$ structure, with less strict classification of gene groups and excluding all ribosomal genes. In addition to genes with above $95 \%$ of transcripts present in oocyte until blastula stage (original analysis), genes with above $70 \%$ of transcripts present in oocyte and 1-2 cell were also included as degrading. Likewise, in addition to genes with above $95 \%$ of transcripts present in blastula and gastrula stage (original analysis), genes with above $70 \%$ of transcripts present in gastrula alone were also included as activating. Blastula stage may contain both maternal and zygotic transcripts; therefore including this stage in the less strict criteria for classification resulted in a number of genes that fell into more than 1 category. Therefore the less strict classification included transcripts of high proportion in oocyte and 1-2 cell or gastrula. For genes regarded as stable, the required proportion of transcripts in each of the four developmental stages (oocyte, 1-2 cell, blastula and gastrula) was extended from $25 \pm 15 \%$ to $25 \pm 20 \%$. a) Overview of number of genes with $3^{\prime} U T R$ isoforms (y-axis) within the whole dataset, and within genes with degrading, stable and activating transcripts (x-axis). The bar to the left within each category represents the total number of genes for that category, and the bar to the right represents the corresponding number of genes with $3^{\prime} U T R$ isoforms. Percentages of genes with $3^{\prime} U T R$ isoforms within each group are indicated by the number on top of the bars. b) $3^{\prime} U T$ TR-lengths of degrading, stable and activating transcripts. Different letters represent significant difference in $3^{\prime} U T R$ length. All data are shown as mean with SEM. N =69, 57 and 29 for degrading, stable and activating transcripts, respectively. c) Proportion (\%) of degrading, stable and activating transcripts that contain different polyadenylation motifs (AATAAA, ATTAAA, AGTAAA, TATAAA, CATAAA, GATAAA, AATATA, AATACA, AATAGA, ACTAAA, AAGAAA and AATGAA). d) Proportion (\%) of degrading, stable and activating transcripts that contain more than one of the motifs shown in c). $\mathrm{N}=69,57$ and 29 for degrading, stable and activating transcripts, respectively.

Additional file 6: Contigs based on clustered sequences. This file contains clustered sequences from all libraries, with given contig name. The contig name can be linked to annotation and accession number in [Additional file 7].

Additional file 7: Contig annotations. This file shows the mapping of EST-contigs to the Atlantic cod genome. Contig annotations for the 257 genes analysed in this study are shown.

Additional file 8: Gene Ontology annotation based on SwissProt BLAST hits. This file contains Gene Ontology (GO) annotation based on SwissProt BLAST hits. 1) SwissProt gene symbol hit, 2) Ensembl gene, 3) Ensembl annotation, 4) SwissProt hit gene names, 5) SwissProt hit evalue, 6) SwissProt hit score, 7) Total SwissProt hits in the whole predicted gene set, 8) GO UniProtKB, 9) GO gene symbol, 10) GO number, 11) GO reference, 12) GO gene name, 13) GO alternative gene symbols, 14) Counter.

Additional file 9: Gene Ontology annotation based on UniRef90 BLAST hits. This file contains Gene Ontology annotation based on UniRef90 BLAST hits. 1) UniRef hit, 2) Ensembl gene, 3) Ensembl annotation, 4) UniRef90 hit, 5) UniRef90 hit e-value, 6) UniRef90 hit score, 7) Total UniRef90 hits in the whole predicted gene set, 8) GO UniRef, 9) GO gene name, 10) GO number, 11), GO gene description, 12) Counter.

\section{Competing interests}

The authors declare that they have no competing interests.

\section{Authors' contributions}

LK performed RNA isolation, QPCR analysis, in silico analysis of sequences that were mapped to the cod genome and drafted the manuscript. AW and GLT designed the study. AW and RBE sampled eggs/embryos and participated in the in silico analysis and manuscript preparation. AW designed the CDNA libraries for cod egg and developmental stages and HK and RR performed library sequencing. KM and TF carried out bioinformatical processing of sequence raw data. ØD provided guidance and participated in data analyses. All authors read and approved the final manuscript. 


\section{Acknowledgements}

This work was funded by the EU-project LIFECYCLE [56]. We would like to thank Heidi Kongshaug for constructing CDNA libraries for cod egg and early developmental stages, the Norwegian Microarray Consortium for providing guidance with analyses and publication of microarray data, Dr. Stein Mortensen for drawing Figure 1, Dr. Craig Morton for correcting written english language and Prof. Jon Vidar Helvik and Dr. Eva Andersson for providing help and guidance throughout the process.

\section{Author details}

'Institute of Marine Research, P. O. Box 1870, Nordnesgaten 50, 5817 Bergen, Norway. ${ }^{2}$ Max Planck Institute for Molecular Genetics, Ihnestrasse 63-73, D-14195 Berlin-Dahlem, Germany. ${ }^{3}$ Max-Planck Genome centre, MPI fuer Pflanzenzüchtungsforschung, Carl-von-Linné-Weg 10, D-80829 Koeln, Germany.

Received: 19 March 2012 Accepted: 29 August 2012 Published: 1 September 2012

\section{References}

1. Kjørsvik E, Mangor Jensen A, Holmefjord I: Egg quality in fishes. Adv Mar Biol 1990, 26:71-113.

2. Brooks $S$, Tyler CR, Sumpter JP: Egg quality in fish: what makes a good egg? Rev Fish Biol Fisher 1997, 7(4):387-416.

3. Kjesbu OS, Solemdal P, Bratland P, Fonn M: Variation in annual egg production in individual captive Atlantic cod (Gadus morhua). Can J Fish Aquat Sci 1996, 53(3):610-620.

4. Bobe J, Labbé C: Egg and sperm quality in fish. Gen Comp Endocrinol 2010, 165(3):535-548.

5. Evsikov AV, Marín de Evsikova C: Evolutionary origin and phylogenetic analysis of the novel oocyte-specific eucaryotic translation initiation factor 4E in Tetrapoda. Dev Genes Evol 2009, 219(2):111-118.

6. Aanes $\mathrm{H}$, Winata $\mathrm{CL}$, Lin CH, Chen JP, Srinivasan KG, Lee SG, Lim AY, Hajan HS, Collas P, Bourque G, Gong Z, Korzh V, Aleström P, Mathavan S: Zebrafish mRNA sequencing deciphers novelties in transcriptome dynamics during maternal to zygotic transition. Genome Res 2011, 21(8):1328-1338.

7. Voeltz GK, Steitz JA: AUUUA sequences direct mRNA deadenylation uncoupled from decay during Xenopus early development. Mol Cell Biol 1998, 18(12):7537-7545.

8. Paillard L, Omilli F, Legagneux V, Bassez T, Maniey D, Osborne HB: EDEN and EDEN-BP, a cis element and an associated factor that mediate sequence-specific mRNA deadenylation in Xenopus embryos. EMBO J 1998, 17(1):278-287.

9. Tadros W, Lipshitz HD: The maternal-to-zygotic transition: a play in two acts. Development 2009, 136:3033-3042.

10. Newport J, Kirschner M: A major developmental transition in early Xenopus embryos 1: characterization and timing of cellular changes at the midblastula stage. Cell 1982, 30(3):675-686.

11. Newport J, Kirschner M: A major developmental transition in early Xenopus embryos: 2: control of the onset of transcription. Cell 1982, 30(3):687-696

12. Kane DA, Kimmel CB: The zebrafish midblastula transition. Development 1993, 119(2):447-456.

13. Kimmel CB, Ballard WW, Kimmel SR, Ullmann B, Schilling TF: Stages of embryonic development of the zebrafish. Dev Dyn 1995, 203(3):253-310.

14. Kraeussling M, Wagner TU, Schartl M: Highly asynchronous and asymmetric cleavage divisions accompany early transcriptional activity in pre-blastula Medaka embryos. PLoS One 2011, 6(7):e21741.

15. Bachvarova R, De Leon V: Polyadenylated RNA of mouse ova and loss of maternal RNA in early development. Dev Biol 1980, 74(1):1-8.

16. Piko L, Clegg KB: Quantitative changes in total RNA, total poly (A), and ribosomes in early mouse embryos. Dev Biol 1982, 89(2):362-378,

17. Mathavan S, Lee SG, Mak A, Miller LD, Murthy KR, Govindarajan KR, Tong Y, Wu YL, Lam SH, Yang H, Ruan Y, Korzh V, Gong Z, Liu ET, Lufkin T: Transcriptome analysis of zebrafish embryogenesis using microarrays. PLoS Genet 2005, 1(2):260-276.

18. Giraldez AJ, Mishima Y, Rihel J, Grocock RJ, Van Dongen S, Inoue K, Enright AJ, Schier AF: Zebrafish MiR-430 promotes deadenylation and clearance of maternal mRNAs. Science 2006, 312(5770):75-79.
19. Drivenes O, Edvardsen RB, Taranger GL: Gene expression profiling of Atlantic cod (Gadus morhua) embryogenesis using microarray. Marine Biotechnol 2011, doi:10.1007/s10126-011-9399-y.

20. Olsvik PA, Holen E: Characterization of an Atlantic cod (Gadus morhua) embryonic stem cell cDNA library. BMC Research Notes 2009, 2(74). doi:10.1186/1756-0500-2-74

21. Evsikov AV, Graber JH, Brockman JM, Hampl A, Holbrook AE, Singh P, Eppig $\mathrm{JJ}$, Solter D, Knowles BB: Cracking the egg: molecular dynamics and evolutionary aspects of the transition from the fully grown oocyte to embryo. Genes Dev 2006, 20:2713-2727.

22. Bai J, Solberg C, Fernandes JMO, Johnston IA: Profiling of maternal and developmental-stage specific mRNA transcripts in Atlantic halibut Hippoglossus hippoglossus. Gene 2007, 386(1-2):202-210.

23. Devonshire AS, Elaswarapu R, Foy CA: Evaluation of external controls for the standardization of gene expression biomarker measurements. BMC Genomics 2010, 11:662

24. Star B, Nederbragt AJ, HJentoft S, Grimholt U, Malmstrøm M, Gregers TF, Rounge TB, Paulsen J, Solbakken MH, Sharma A, Wetten OF, Lanzén A, Winer R, Knight J, Vogel JH, Aken B, Andersen O, Lagesen K, ToomingKlunderud A, Edvardsen RB, Tina KG, Espelund M, Nepal C, Previti C, Karlsen BO, Moum T, Skage M, Berg PR, Giøen T, Kuhl H, et al: The genome sequence of Atlantic cod reveals a unique immune system. Nature 2011, 477(7363):207-210.

25. Mittelholzer $C$, Andersson E, Consten D, Hirai T, Nagahama Y, Norberg B: 20ß-hydroxysteroid dehydrogenase and CYP19A1 are differentially expressed during maturation in Atlantic cod (Gadus morhua). J Mol Endochrinol 2007, 39:319-328.

26. Olsvik PA, Søfteland L, Lie KK: Selection of reference genes for qRT-PCR examination of wild populations of Atlantic cod Gadus morhua. BMC Research Notes 2008, 1:47.

27. Donnison M, Pfeffer PL: Isolation of genes associated with developmentally competent bovine oocytes and quantitation of their levels during development. Biol Reprod 2004, 71:1813-1821.

28. Tingaud-Sequeira A, Chauvigné F, Lozano J, Aqulleiro MJ, Asensio E, Cerdà J: New insights into molecular pathways associated with flatfish ovarian development and atresia revealed by transcriptional analysis. BMC Genomics 2009, 10:434

29. Shen-Orr SS, Pilpel Y, Hunter CP: Composition and regulation of maternal and zygotic transcriptomes reflects species-specific reproductive mode. Genome Biol 2010, 11(6):R58.

30. Nagler JJ: In vivo treatment with cycloheximide or actinomyciin D inhibits early embryonic development in rainbow trout (Oncorhynchus mykiss). Fish Physiol Biochem 2000, 22(1):61-66.

31. Giraldez AJ, Cinalli RM, Glasner ME, Enright AJ, Thomson JM, Baskerville S, Hammond SM, Bartel DP, Schier AF: MicroRNAs regulate brain morphogenesis in zebrafish. Science 2005, 308(5723):833-838.

32. Mommens M, Fernandes JM, Bizuayehu TT, Bolla SL, Johnston IA, Babiak I: Maternal gene expression in Atlantic halibut (Hippoglossus hippoglossus L.) and its relation to egg quality. BMC Research Notes 2010, 3:138.

33. Montero J-A, Heisenberg C-P: Gastrulation dynamics: cells move into focus. Trends Cell Biol 2004, 14(11):620-627.

34. Revil T, Gaffney D, Dias C, Majewski J, Jerome-Majewska LA: Alternative splicing is frequent during early embryonic development in mouse. $B M C$ Genomics 2010, 11:399.

35. Schier AF: The maternal-zygotic transition: death and birth of RNAs. Science 2007, 316(5823):406-407.

36. Ledda M, Di Croce M, Bedini B, Wannenes F, Corvaro M, Boyl PP, Caldarola S, Loreni F, Amaldi F: Effects of $3^{\prime} U T R$ length on the translational regulation of 5/-terminal oligopyrimidine mRNAs. Gene 2005, 344:213-220.

37. Tanguay RL, Gallie DR: Translational efficiency is regulated by the length of the 3' untranslated region. Mol Cell Biol 1996, 16(1):146-156.

38. Chen C-Y, Chen S-T, Juan H-F, Huang H-C: Lengthening of $3^{\prime} U T R$ increases complexity in animal evolution. 2010. Available from Nature Precedings http://hdl.handle.net/10101/npre.2010.4915.1.

39. Ji Z, Lee JY, Pan Z, Jiang B, Tian B: Progressive lengthening of $3^{\prime}$ untranslated regions of mRNAs by alternative polyadenylation during mouse embryonic development. PNAS 2009, 106(17):7028-7033.

40. Bailey $T L$, Elkan C: Fitting a mixture model by expectation maximization to discover motifs in biopolymers. Proceedings of the Second International Conference on Intelligent Systems for Molecular Biology 1994, 2:28-36. 
41. Fox $C A$, Sheets $M D$, Wickens $M P$ : Poly $(A)$ addition during maturation of frog oocytes: distinct nuclear and cytoplasmic activities and regulation by the sequence UUUUUAU. Genes Dev 1989, 3:2151-2162.

42. McGrew LL, Dworkin-Rastl E, Dworkin MB, Richter JD: Poly(A) elongation during Xenopus oocyte maturation is required for translational recruitment and is mediated by a short sequence element. Genes Dev 1989, 3:803-815

43. Colgan DF, Manley JL: Mechanism and regulation of mRNA polyadenylation. Genes Dev 2011, 11:2755-2766.

44. Villalba A, Coll O, Gebauer F: Cytoplasmic polyadenylation and translational control. Curr Opin Genet Dev 2011, 21:452-457.

45. Beaudoing E, Freier S, Wyatt JR, Claverie J-M, Gautheret D: Patterns of variant polyadenylation signal usage in human genes. Genome Res 2000, 10(7):1001-1010.

46. Edwalds-Gilbert $\mathrm{G}$, Veraldi KL, Milcarek C: Alternative poly(A) site selection in complex transcription units: means to an end? Nucleic Acids Res 1997 25(13):2547-2561.

47. Hall TE, Smith $P$, Johnston IA: Stages of embryonic development in the Atlantic cod Gadus morhua. J Morphol 2004, 259:255-270.

48. Kuhl H, Sarropoulou E, Tine M, Kotoulas G, Magoulas A, Reinhardt R: A comparative BAC map for the gilthead sea bream (Sparus aurata L.). J Biomed Biotechnol 2011, 2011:329025.

49. Ewing B, Hillier L, Wendl MC, Green P: Base-calling of automated sequencer traces using Phred. 1. Accuracy assessment. Genome Res 1998, 8(3):175-185.

50. Ewing B, Green P: Base-calling of automated sequencer traces using Phred. 1. Error probabilities. Genome Res 1998, 8(3):186-194.

51. Malde K, Schneeberger K, Coward E, Jonassen I: RBR: library-less repeat detection for ESTs. Bioinformatics 2006, 22(18):2232-2236.

52. Pertea G, Huang X, Liang F, Antonescu V, Sultana R, Karamycheva S, Lee $Y$, White J, Cheung F, Parvizi B, Tsai J, Quackenbush J: TIGR Gene Indices clustering tools (TGICL): a software system for fast clustering of large EST datasets. Bioinformatics 2003, 19(5):651-652.

53. The cod genome webpage. www.codgenome.no.

54. Ashburner M, Ball CA, Blake JA, Botstein D, Butler H, Cherry JM, Davis AP, Dolinski K, Dwight SS, Eppig JT, Harris MA, Hill DP, Issel-Tarver L, Kasarskis A, Lewis S, Matese JC, Richardson JE, Ringwald M, Rubin GM, Sherlock G: Gene Ontology: tool for the unification of biology. Nat Genet 2000, 25(1):25-29.

55. Gene ontology annotation files. http://www.geneontology.org/.

56. The LIFECYCLE project web page. http://www.lifecycle-fp7.eu/.

57. Robaliano J, Joshi B, Fahrenkrug SC, Jagus R: Two zebrafish elF4E family members are differentially expressed and functionally divergent. $J$ Biol Chem 2004, 279(11):10532-10541.

58. Von der Haar T, Gross JD, Wagner G, McCarthy JEG: The mRNA cap-binding protein elF4E in post-transcriptional gene expression. Nat Struct Mol Biol 2004, 11(6):503-511.

59. Raught B, Gingras A-C, Gygi SP, Imataka H, Morino S, Gradi A, Aebersold $\mathrm{R}$, Sonenberg N: Serum-stimulated, rapamycin-sensitive phosphorylation sites in the eukaryotic translation initiation factor 4GI. EMBO J 2000, 19(3):434-444.

60. Veenstra GC, Destrée OHJ, Wolffe AP: Translation of maternal TATAbinding protein mRNA potentiates basal but not activated transcription in Xenopus embryos at the midblastula transition. Mol Cell Biol 1999, 19(12):7972-7982.

61. Bártfai R, Balduf C, Hilton T, Rathmann $Y$, Hadzhiev $Y$, Tora L, Orbán L, Müller F: TBP2, a vertebrate-specific member of the TBP family, is required in embryonic development of zebrafish. Curr Biol 2004, 14(7):593-598.

62. Ferg M, Sanges R, Gehrig J, Kiss J, Bauer M, Lovas A, Szabo M, Yang L, Straehle U, Pankratz MJ, Olasz F, Stupka E, Müller F: The TATA-binding protein regulates maternal mRNA degradation and differential zygotic transcription in zebrafish. EMBO J 2007, 26(17):3945-3956.

63. Schulte-Merker $\mathrm{S}, \mathrm{Ho}$ RK, Herrmann BG, Nüsslein-Volhard C: The protein product of the zebrafish homologue of the mouse $T$ gene is expressed in nuclei of the germ ring and the notochord of the early embryo. Development 1992, 116:1021-1032.

64. Schulte-Merker $\mathrm{S}$, van Eeden FJ, Halpern ME, Kimmel CB, Nüsslein-Volhard C: no tail ( $n t l)$ is the zebrafish homologue of the mouse $T$ (Brachyury) gene. Development 1994, 120(4):1009-1015. doi:10.1186/1471-2164-13-443

Cite this article as: Kleppe et al:: Maternal 3'UTRs: from egg to onset of zygotic transcription in Atlantic cod. BMC Genomics 2012 13:443.

\section{Submit your next manuscript to BioMed Central and take full advantage of:}

- Convenient online submission

- Thorough peer review

- No space constraints or color figure charges

- Immediate publication on acceptance

- Inclusion in PubMed, CAS, Scopus and Google Scholar

- Research which is freely available for redistribution

Submit your manuscript at www.biomedcentral.com/submit
C) BioMed Central 